\title{
Continuous and interval aerobic sessions: effects on triglyceride concentrations
}

\author{
Sessões aeróbicas intervaladas e contínuas: efeitos sobre as concentrações de \\ triglicerídeos
}

\section{AUTHOR'S \\ Éder Santiago ${ }^{1}$ (D) \\ Rochelle Rocha Costa ${ }^{1}$ (D) \\ Rodrigo Sudatti Delevatti ${ }^{2}$ (D) \\ Cláudia Gomes Bracht ${ }^{1}$ (D) \\ Artur Avelino Birk Preissler ${ }^{1}$ (D) \\ Gustavo Silveira ${ }^{1}$ (D) \\ Danielle Girolometto Fracalossi ${ }^{1}$ (D) \\ Eli Silveira Júnior ${ }^{1}$ (D) \\ Vitória de Mello Bones da Rocha ${ }^{1}$ (D) \\ Bruna Machado Barroso ${ }^{1}$ (D) \\ Thaís Reichert ${ }^{1}$ (D) \\ Luiz Fernando Martins Kruel ${ }^{1}$ \\ 1 Universidade Federal do Rio Grande do Sul. \\ Porto Alegre, Rio Grande do Sul, Brasil. \\ 2 Universidade Federal de Santa Catarina. \\ Florianópolis, Santa Catarina, Brasil.}

\section{CORRESPONDING}

Eder Sulei Santiago da Silva

edersantiagosilva@hotmail.com

Rua Felizardo, 750 - Jardim Botânico, Porto

Alegre, Rio Grande do Sul, Brasil.

CEP: 90690-200.

DOI

$10.12820 /$ rbafs. $25 \mathrm{e} 0173$

\begin{abstract}
The regular practice of physical exercise, primarily aerobic, has been recommended as a component of the non-pharmacological treatment for dyslipidemias. However, there is a lack of studies in the literature comparing the acute effects of different aerobic exercise models (continuous and interval) on triglycerides concentrations. The purpose of the present study was to analyze the magnitude of change on triglycerides concentrations after a single session of interval and continuous exercise in persons with dyslipidemia. This study was a randomized crossover clinical trial. Fifteen volunteers performed two different aerobic sessions, a continuous and an interval session. The intensity of the continuous session was maintained between $85-90 \%$ of the heart rate at anaerobic threshold $\left(\mathrm{HR}_{\mathrm{AT}}\right)$. The interval session consisted of 9 sets of 4 minutes at $85-90 \% \mathrm{HR}_{\mathrm{AT}}$ followed by one minute below $85 \% \mathrm{HR}_{\mathrm{AT}}$ Triglycerides concentrations were assessed before, immediately after and at the end of 30 minutes after all sessions. Both sessions models resulted in alterations in triglycerides concentrations immediately after exercise $(p=0.005)$, without difference between them $(p=0.446)$. Continuous session increased triglycerides concentrations by $34.9 \%$ from pre-exercise to immediately post-exercise and the interval session, by $7.9 \%$. Thirty minutes after exercise, triglyceride concentrations showed no significant difference in relation to the pre-exercise and immediately after exercise moments in both session models. Therefore, it is concluded that aerobic exercise promotes responses in triglycerides concentrations of dyslipidemic patients, independently of the exercise method, either continuous or interval.
\end{abstract}

Keywords: Lipids; Training; Dyslipidemia; Randomized clinical trial.

RESUMO

A prática regular de exercício físico, principalmente aeróbico, tem sido recomendado como componente de tratamento não farmacológico contra as dislipidemias. No entanto, a literatura carece de estudos comparando os efeitos agudos de diferentes modelos de exercício aeróbico (contínuo e intervalado) sobre as concentraçóes de triglicerídeos. O objetivo do presente estudo foi analisar a magnitude de mudança sobre as concentraçooes de triglicerídeos após uma sessão de exercício intervalado e contínuo em pessoas com dislipidemia. Além disto, este estudo se caracteriza por ser um ensaio clínico randomizado cruzado. Nele, quinze voluntários realizaram duas sessões aeróbicas diferentes, uma sessão contínua e outra intervalada. A intensidade da sessão contínua se manteve entre 85-90\% da frequência cardíaca referente ao limiar anaeróbico (HRAT). A sessão intervalada consistiu de 9 séries de quatro minutos entre 85-90\% da HRAT seguidas de um minuto abaixo de $85 \%$ da HRAT. As concentraçôes de triglicerídeos eram verificadas antes, imediatamente após e passados 30 minutos do término de todas as sessões. Ambos os modelos de sessôes resultaram em alteraçôes das concentraçôes de triglicerídeos imediatamente após exercício $(p=0,005)$, sem diferença entre elas $(p=0,446)$. A sessão contínu aumentou as concentraçóes de triglicerídeos em $43,9 \%$ do pré-exercicio para imediatamente após o exercício e a sessão intervalada aumentou em 7,93\% no mesmo período. Trinta minutos após o exercício, as concentraçôes de triglicerídeos não apresentaram diferença significativa em relação aos momentos pré-exercício e imediatamente após o exercício em ambos os modelos de sessão. Assim, conclui-se que o exercício aeróbico promove alterações nas concentraçôes de triglicerídeos de pacientes dislipidêmicos, independentemente do método de exercicio, se contínuo ou intervalado.

Palavras-chave: Lipideos; Treinamento; Dislipidemia; Ensaio clínico randomizado.

\section{Introduction}

Dyslipidemias can be defined as heterogeneous disorders in lipid metabolism arising from multiple etiologies, which results in alterations in blood lipoproteins (low and high-density lipoprotein, respectively LDL and HDL) and lipids concentrations (total cholesterol and triglycerides, respectively TC and TG) ${ }^{1}$. The lipid deposition on endothelial arteries induces the forma- 
tion of atherosclerosis, increasing the risk of cardiovascular events, such as myocardial infarction, stroke and peripheral vascular disease. Within this scenario, it becomes important to control the levels of the main lipids, namely: cholesterol and TG.

The regular practice of physical exercise, primarily aerobic, has been recommended as a component of the non-pharmacological treatment of dyslipidemias ${ }^{2}$. In this context, structured walking and running, with volume and intensity control, progression strategies and appropriate methods (i.e. continuous or interval) are capable of promoting important cardiovascular and metabolic benefits to the practitioner ${ }^{3}$. Indeed, studies have reported reductions in plasma TG after exercise training ${ }^{4,5}$. Such favorable changes may be partially attributed to the short-term lipid modifications that can occur after a single session of aerobic exercise. In this sense, evidences show that the practice of a single aerobic exercise session promotes acute metabolic effects with significant changes in the lipid profile, including reductions in TG concentrations $(\mathrm{TGC})^{7-9}$.

However, all the studies evaluating acute aerobic exercise effects used the continuous method for training prescription. Considering that dyslipidemic patients present lower cardiorespiratory fitness than their normolipidemic pairs and lower tolerance to high-intensity exercise ${ }^{10}$, the interval method seems to be an interesting strategy, allowing these patients to achieve high intensities during certain periods, interspersed with recovery periods. In addition, as this a dynamic method, it may lead to a greater training adherence, which is important for the cardiometabolic population. However, the effectiveness of the interval method in TGC is not yet known.

To optimize the structuring of aerobic exercise training in the treatment of dyslipidemia, it is important to better understand the acute lipid responses to different methods, because lipid chronic effects are dependent of acute stimuli ${ }^{11}$. However, as the literature only presents the TGC responses to continuous aerobic sessions, there is a gap regarding the acute effects of different models of aerobic exercise sessions, i.e. interval, on TGC of individuals with dyslipidemia. Thus, the objective of this study was to verify the magnitude of change on triglycerides concentrations after a single session of interval and continuous exercise in persons with dyslipidemia. We hypothesized that immediately after the aerobic sessions, TGC concentrations would remain unchanged, as demonstrated by previous stud- ies $^{6-9}$, followed by a reduction 30 minutes after exercise, as a response to the decrease in the route of TG mobilization from adipose tissue stores to the bloodstream.

\section{Methods}

This study was characterized as a randomized crossover clinical trial in which dyslipidemic patients performed in a randomized order a continuous and an interval aerobic exercise sessions.

Participants were recruited from advertisements for the general community of Porto Alegre (Brazil). To participate in the study, it was necessary to be over 18 years and to have any type of dyslipidemia. People affected by any musculoskeletal impairment that compromised walking activity could not participate in the study. Participants were instructed about the objectives, risks and procedures involved in the study. The Ethics Committee of Universidade Federal do Rio Grande do Sul approved the study (protocol 1.571.144), which is in accordance with the Helsinki Declaration. All participants completed an informed consent form.

The sample size was determined using $G^{*}$ Power software (version 3.1; Universität Düsseldorf, Düsseldorf, Germany) employing a power of 0.95 (significance level of .05 and an effect size of 0.32), based on the data research of Ferguson et al. ${ }^{12}$. This calculation demonstrated the need for a minimum (n) sample number of 28 participants. As this study is crossed, forming two groups of the same participants, the participation of at least 14 volunteers was necessary for each model of training session. The study subjects were participating in an extension project at the Universidade Federal do Rio Grande do Sul, comprising 18 individuals. Of these, 15 completed the pre-training and accepted to participate in the experimental exercise sessions.

Initially, the participants performed an adaptation period called "run-in". For this, all participants were previously familiarized with the Borg Scale of Perceived Exertion ${ }^{13}(6-20)$. This four-week period aimed at assessing adherence to the study and providing minimal physical conditioning in order to allow participation in the two models of experimental sessions to be later performed. During the run-in period, the participants were instructed to walk or run according to the Borg Scale of Perceived Exertion ${ }^{13}$ (RPE - Table 1).

Body mass and height were measured using a Filizola analogue scale (resolution of $0.1 \mathrm{~kg}$ ) and a Filizola metal stadiometer (resolution of $1 \mathrm{~mm}$ ) respectively. With these data, body mass index (BMI) was calculat- 
ed. Waist circumference measurement was performed at the midpoint between the iliac crest and the last rib (Cescorf's flexible and inelastic tape measure with resolution of $1 \mathrm{~mm}$ ). Lastly, the measurement of seven skinfolds was performed (triceps, subscapular, suprailiac, abdominal, mid axillary, thigh and calf) with an adipometer (Cescorf with resolution of $1 \mathrm{~mm}$ ). With these values, body density was estimated using the appropriate equations for men and women ${ }^{14}$, and subsequently, body fat percentage was also estimated ${ }^{15}$. The resulting value of the seven skinfolds sum was considered as the sum of the skinfolds. All anthropometric measurements were performed by the same trained evaluator.

Table 1 - Run-in period.

\begin{tabular}{lccc}
\hline Week & Duration $(\min )$ & Training Method & Intensity \\
\hline 1 & 20 & Continuous & RPE 13 \\
2 & 25 & Continuous & RPE 13 \\
3 & 30 & Continuous & RPE 13 \\
4 & 35 & Interval & 6 x (4 min RPE 11 + 1 \\
& & & min RPE 15) \\
\hline
\end{tabular}

$\mathrm{RPE}=$ rating of perceived exertion (Borg's Scale).

After the run-in period, the participants underwent a progressive exercise test on a treadmill (Inbramed, Porto Alegre, Brazil). In this test, the heart rate deflection point (HRDP) was verified and because it corresponds to the anaerobic threshold $(\mathrm{AT})^{16}$, a percentage of this point was used as reference for the exercise intensity prescription of the experimental sessions. The test protocol consisted of an initial velocity of $3 \mathrm{~km} . \mathrm{h}$ ${ }^{1}$ for 3 minutes with an increase of $1 \mathrm{~km} \cdot \mathrm{h}^{-1}$ every 2 minutes until the participant's voluntary manifestation of exhaustion ${ }^{17}$. The test was considered valid when at least one of the following criteria was reached at the end of the test: 1) obtainment of the estimated maximum heart rate $\left(\mathrm{HR}_{\max }-220\right.$-age); 2$)$ obtainment of a respiratory exchange ratio greater than $1.1 ; 3$ ) Borg's rating of perceived exertion greater than 17 (very intense) ${ }^{18}$. Throughout the test the slope was kept fixed at $1 \%$. Heart rate was monitored by a cardiac monitor (FT1 Polar, Finland), and recorded at every 10 seconds. After the test, the HRDP was determined according to the methodology proposed by Conconi et $\mathrm{al}^{16}$.

After this evaluation, the two experimental sessions (continuous or interval), which order was determined by simple randomization, were scheduled. Randomization process was performed in the online software www.randomization.com by an impartial individual, not involved in the study, in order to maintain the allocation concealment and the blindness of the researchers regarding this process.

Exercise sessions were conducted during the afternoon, between 5 and 7 p.m. The minimum interval between sessions was 48 hours. Participants were instructed to maintain their usual eating habits and their regular medications in the 24 hours prior to the sessions.

In the experimental sessions, initially the participants rested for five minutes, in which they reported their use of medications and food intake in the last 24 hours. If the participant reported any behavior which was different than his/her usual habits, the experimental session was rescheduled. Subsequently, the first measurement of TGC was performed using a capillary blood sample using the Accutrend Plus equipment (Roche, Portugal) according to the manufacturer's instructions. Once the pre-exercise collection was completed, the session randomly defined was performed and, at the end of the session, a new collection was performed to record the immediately post-exercise data. After these procedures, the participants rested (sitting in silence) for 30 minutes and a final TGC collection was performed.

On the second evaluation day, the participant was submitted to the same protocol, with the other method of aerobic exercise session performed (continuous or interval), according to the previous randomization. The intensity of the continuous session was maintained between $85-90 \%$ of the heart rate at anaerobic threshold (HRAT), during 45 minutes. The interval session consisted of 9 sets of 4 minutes at $85-90 \%$ HRAT followed by one minute below $85 \%$ HRAT.

Sample characterization data are presented as mean and standard deviation. Mean, standard error, and the lower and upper limits of confidence interval (95\% CI) were adopted for the outcome data presentation (TGC). For the comparison of the outcome in the different moments (pre-, post- and 30 min post-exercise) and sessions (continuous and interval) the Generalized Estimating Equations method was used, with Bonferroni post hoc test. The significance level adopted was $\alpha$ $=0.05$. The analyses were conducted in the statistical package SPSS version 22.0.

In addition, an assessment was made of the rate of individuals who responded favorably to exercise and those who did not respond favorably to exercise. Prevalence of responders was obtained according to a theoretical model applied in previous published studies ${ }^{19,20}$. 
Nonetheless, due to the impossibility of two pre-session measures of TGC in the present study, we did not calculate the reliability intrasubject (typical error) as suggested for this kind of analysis by the studies previously cited. Aiming to minimize this limitation, we considered as acceptable individual effects, the values of the technical error of measurement (TE). The TE for this analysis was considered $3.4 \%$ according to the equipment manufacturer. So, non-responder individuals were defined as those who did not show an increase or reduction greater than two times the TE. Responders were defined as those who showed increase or decrease greater than two times the TE. Changes greater than two points above the TE indicate a high probability that the response is favorable to the physiological adaptation and/or biological variability ${ }^{21}$. Furthermore, the distribution of responders between the continuous and interval methods was compared using chi-squared test.

\section{Results}

Fifteen participants completed the run-in period and participated in the interventions (Table 2), eight of them presented hypertriglyceridemia.

Table 2 - Sample characterization data.

\begin{tabular}{lc}
\hline & $\begin{array}{c}\text { Mean } \pm \text { Standard } \\
\text { Deviation }\end{array}$ \\
\hline Age (years) & $60 \pm 12.2$ \\
Sex $(\mathrm{M} / \mathrm{F})$ & $9 / 6$ \\
Height $(\mathrm{m})$ & $1.66 \pm 0.1$ \\
Body mass $(\mathrm{Kg})$ & $77.67 \pm 15.7$ \\
Body mass index $\left(\mathrm{Kg}^{-2} \mathrm{~m}^{-2}\right.$ & $27.94 \pm 3.8$ \\
Waist circumference $(\mathrm{cm})$ & $98.05 \pm 15.4$ \\
Waist-to-height ratio & $0.59 \pm 0.1$ \\
\% fat & $25.71 \pm 8.2$ \\
L7skinfolds (mm) & $139.15 \pm 36.5$ \\
Lipid-lowering drugs in use (n) & \\
Atorvastatin & 1 \\
Ciprofibrate & 1 \\
Fenofibrate & 1 \\
Gemfibrozil & 1 \\
Ezetimibe & 2 \\
Rosuvastatin & 4 \\
Simvastatin & 3 \\
Non-use of lipid-lowering medication (n) & 4 \\
\hline
\end{tabular}

$\Sigma=$ Sum.
The experimental sessions resulted in significant changes in TGC when the moment effect was evaluated (moment factor: $p=0.005$ ), but there was no difference when compared to each other (session factor: $\mathrm{p}=$ 0.446). The session*moment interaction did not show a significant effect $(\mathrm{p}=0.488)$.

In a general analysis, combining both exercise sessions, it was observed that pre-exercise TGC was $276.13 \pm 20.58 \mathrm{mg}^{-1} \mathrm{dl}^{-1}$ (95\%CI: 235.79; 316.47) and significantly increased to $333.82 \pm 26.32 \mathrm{mg} \cdot \mathrm{dl}^{-1}$ (95\%CI: 282.23 ; 385.40) in the immediate post-exercise $(\mathrm{p}=0.005)$, representing an increase of $20.9 \%$. After 30 minutes, there was a non-significant decrease to $297.90 \pm 32.91 \mathrm{mg}^{-1}$ (95\%CI: $233.38 ; 362.42$ ) or $10.7 \%$ drop from the immediate post-exercise, as shown in Figure 1.

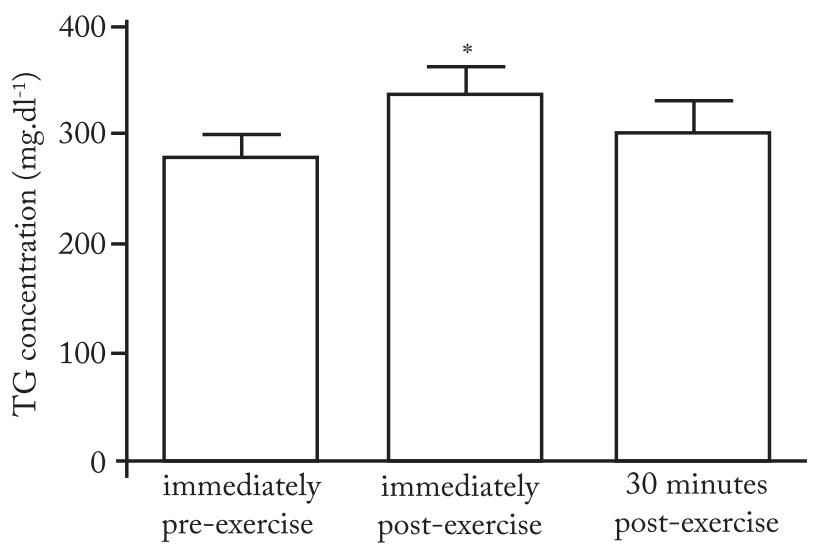

Figure 1 - Mean and standard error of the triglyceride concentrations immediately pre-exercise, immediately post-exercise and 30 minutes after the end of exercise session.

* indicate statistical difference with immediately pre-exercise $(p<0.05)$.

In the analysis of the exercise sessions, the continuous session showed a significant increase in TGC from the pre to the immediate post-exercise, from 265.13 $\pm 27.93 \mathrm{mg}^{-\mathrm{dl}^{-1}}$ (95\%CI: 210.38 ; 319.88) to $357.71 \pm$ 32.77 mg.dl ${ }^{-1}$ (95\%CI: 293.49; 421.94) (+ 34.9\%). At 30 minutes after exercise, TGC returned to the levels close to pre-exercise, of $305.07 \pm 40.32 \mathrm{mg} \cdot \mathrm{dl}^{-1}$ (95\%CI: 226.05 ; 384.09), being $15.3 \%$ higher than pre-exercise and $14.5 \%$ lower than immediately post-exercise. The interval session presented a similar response, with a significant increase from $287.13 \pm 27.70 \mathrm{mg} \cdot \mathrm{dl}^{-1}$ (95\%CI: 232.85 ; 341.42) in the pre-exercise to $309.92 \pm 36.12$ mg.dl ${ }^{-1}(95 \% \mathrm{CI}: 239.13$; 380.72) immediately post-exercise (+ 7.93\%), regressing to $290.73 \pm 30.11 \mathrm{mg} \cdot \mathrm{dl}^{-1}$ (95\%CI: $231.72 ; 349.74)$ at 30 minutes after exercise $(+1.25 \%$ in relation to pre-exercise and $-6.19 \%$ in relation to immediate post-exercise) - Figure 2. 


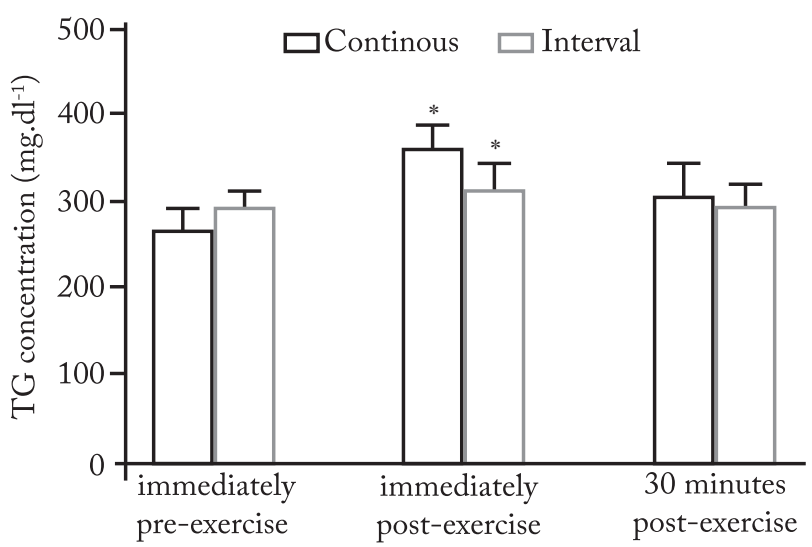

Figure 2 - Mean and standard error of the triglyceride concentrations immediately pre-exercise, immediately post-exercise and 30 minutes after the end of the continuous and interval exercise sessions.

* indicate statistical difference with immediately pre-exercise $(\mathrm{p}<0.05)$.

The individual responsiveness analysis from pre-exercise to immediately post-exercise evidenced that 12 participants were responsive to the continuous protocol and 14 to the interval protocol. Immediately after the continuous session, three participants presented a fall in TGC (varying from -30 to $-163 \mathrm{mg} \cdot \mathrm{dl}^{-1}$ ), whereas the other nine individuals presented increased values (with elevations between 25 and $383 \mathrm{mg} \cdot \mathrm{dl}^{-1}$ ). Immediately after the interval session, five participants presented decreased TGC (ranging from -33 to -152 $\mathrm{mg} \cdot \mathrm{dl}^{-1}$ ), whereas the other nine participants present-

Continous

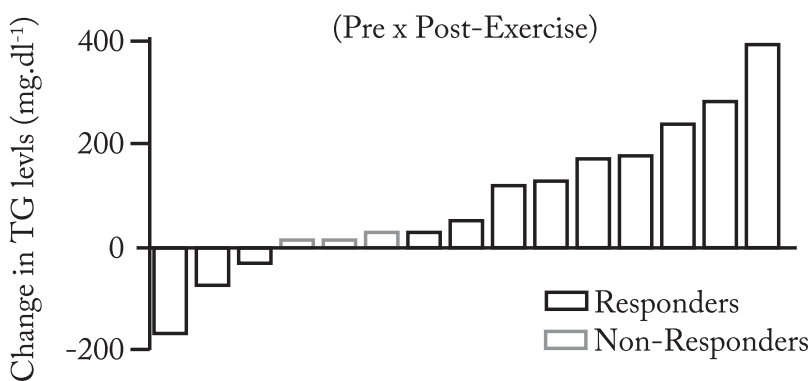

Continous

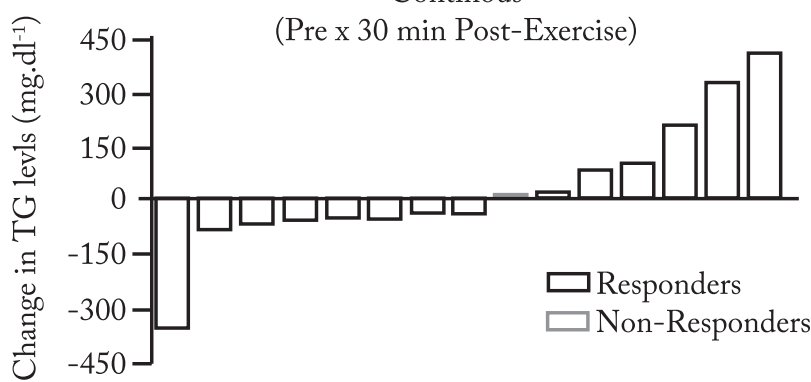

ed an increment (from 30 to $266 \mathrm{mg} \cdot \mathrm{dl}^{-1}$ ). However, significant differences were not observed between the number of responsive participants before and after the continuous and interval protocols $(p=0.283)$.

When individually analyzing the participants in the comparison between pre-exercise and 30 minutes after exercise, 14 participants were responsive to the continuous protocol and 11 participants were responsive to the interval session. Among the 14 participants responsive to the continuous protocol, eight presented a fall in TGC (varying from -31 to $-346 \mathrm{mg} \cdot \mathrm{dl}^{-1}$ ), whereas six presented an increment (from 27 to $408 \mathrm{mg}$.dl $\left.{ }^{1}\right)$. With the interval model, six participants had their TG levels decreased (from -21 to $-245 \mathrm{mg}$. $\mathrm{dl}^{-1}$ ) and the other five had their levels increased (from 18 to 201 mg.dl ${ }^{-1}$ ) - Figure 3. It is highlighted that significant changes were not observed between the number of responsive participants before and after the 30 minutes of the continuous and interval protocols $(\mathrm{p}=0.142)$.

\section{Discussion}

The main finding of the present study was that the interval and continuous aerobic exercise sessions proposed in our study promoted increment in TGC immediately post-exercise, which returned to baseline values 30 minutes after the sessions. Our results are different from what was previously hypothesized, since we expected a maintenance of the values immediately
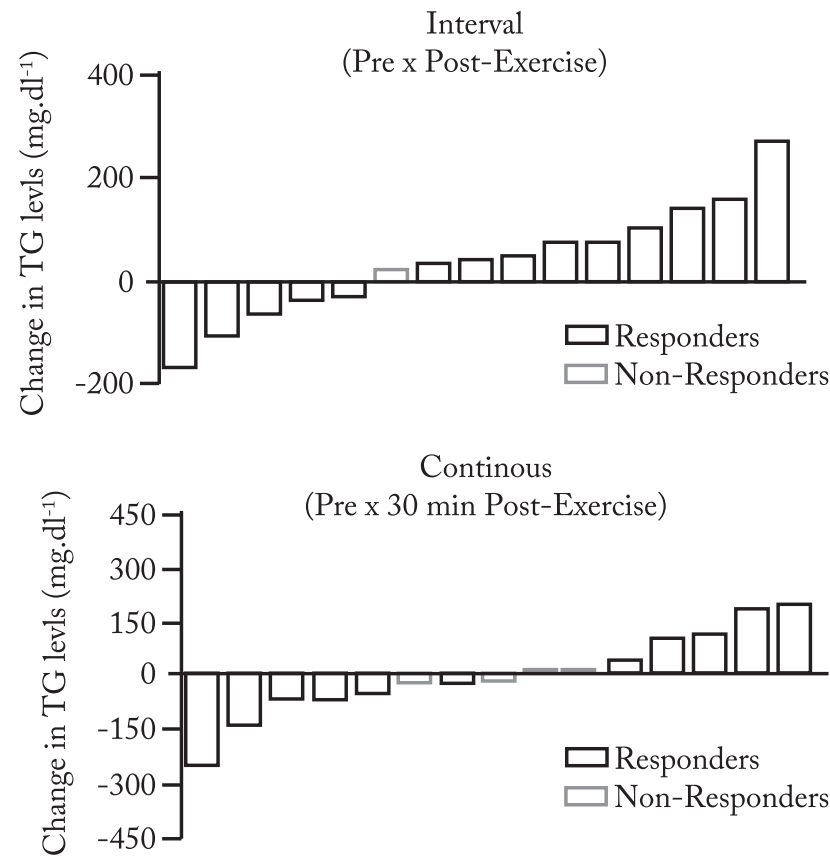

Figure 3 - Individual responsiveness of triglyceride concentrations resulting from continuous and interval sessions. * indicate statistical difference with immediately pre-exercise $(\mathrm{p}<0.05)$. 
after the aerobic sessions, and a significant reduction 30 minutes after exercise. However, TGC 30 minutes after exercise did not differ from pre-exercise or immediately after exercise sessions. That is, TGC returned to pre-session values in only 30 minutes after the end of the sessions. In addition, it was observed that, independently of the exercise method proposed, most participants were responsive to the exercise sessions, in which only four and five participants were not responsive to the continuous and interval protocols, respectively.

Immediately after the aerobic protocols performance, there was a significant TGC elevation, greater than 20\%. We believe that such TG mobilization likely resulted from the adipose tissue stores into the bloodstream, in order to be used as an energy substrate for the exercise performance. This result was different from other studies previously performed with dyslipidemic individuals $s^{6-9}$, which did not find significant differences in the TGC immediately after an aerobic exercise session, only finding changes after longer periods, as 24 and 48 hours after the end of exercise.

According to Brouns \& Van der Vusse ${ }^{22}$, the rate of fatty acids oxidation results from the combination of certain processes for energy obtainment during exercise, as lipolysis of TG in the adipose tissue and of circulating TG in the blood. Therefore, we believe that the increase of TGC immediately after exercise found in the present study may be attributed to the increase of TG synthesis by the liver, promoted by the release of fatty acids from the adipose tissue on the bloodstream, stimulated by the lipoprotein lipase (LPL) enzyme as response to exercise ${ }^{23}$. Given that LPL has a known action on the lipid metabolism by hydrolyzing TG molecules $^{24,25}$, we believe that our findings may be attributed to the increase of LPL activity in the adipose tissue, by mobilizing fat from its stocks into the bloodstream. In fact, LPL activity is strongly related to aerobic exercise practice. Studies found that, at the end of an aerobic exercise session there is an increase in LPL activity for up to $18^{26}$ and 24 hours 9 . Thus, it is believed that acutely the participants of the present study experienced an increase in this enzyme activity on the adipose tissue, and consequently, increased circulating TGC. This hypothesis is in accordance with the findings of Weise et al. ${ }^{9}$, who investigated dyslipidemic post-menopausal women and found increased LPL activity immediately after an aerobic exercise session, with a tendency of increase in TGC.

The maintenance of TGC values 30 minutes after the exercise may be justified by the timing of this anal- ysis. It is possible that 30 minutes had been insufficient to generate a decrease in the route of TG mobilization from adipose tissue stores to the bloodstream, as well as hepatic synthesis. However, although a statistical significance was not found in this result, it is observed a tendency of fall of approximately $11 \%$ in TGC. It is believed that, with a longer analysis period, this lipid reduction would have been higher, and would be supported by the aforementioned studies that found significant reduction 24 hours after the end of exercise, even presenting values lower than those of pre-exercise ${ }^{6,8,9}$.

In this sense, Kantor et al. ${ }^{26}$ showed a significant negative correlation between the changes in LPL activity (from pre- and post-exercise) and TGC, suggesting that LPL increase after exercise may be responsible for the late reduction in TGC. Even so, it is important to highlight that these are only speculations, because in the present study we did not assess LPL activity.

Regarding the models of exercise prescription proposed, continuous and interval, to our knowledge, the present study was the first to compare prescription methods in the lipid response of dyslipidemic patients. Although the prescription of continuous intensity has been analyzed by Crouse et al. ${ }^{7}$, Crouse et al. ${ }^{8}$, Grandjean et $a .^{6}$ and Weise et al. ${ }^{9}$, the protocols were performed with intensities varying from 50 to $80 \%$ of peak oxygen consumption and session durations between 35 and $81 \mathrm{~min}$. In these studies, no changes in TGC were observed immediately after exercise. On the other hand, the continuous protocol of the present study, with 45 min of duration and intensity between 85 and 90\% $\mathrm{HR}_{\mathrm{AT}}$, was effective in promoting significant changes ( $21 \%$ of elevation in TGC). Considering that such intensities and volumes were similar ${ }^{27}$, it is speculated that the reason for the difference in the results obtained is due to the fact that the patients of the four studies above mentioned performed exercise in the fasting state, whereas in the present study the participants were fed (usual feeding), presenting pre-exercise TGC considerably greater. Indeed, LPL activity is acutely regulated by meal ingestion, since its activity increases postprandially in adipose tissue $\mathrm{e}^{28}$, which may have caused the increased post-exercise TGC found in our study.

In an innovative way, the present study demonstrated that a single session of aerobic exercise adopting the interval method was effective in promoting beneficial responses in the lipid metabolism, with TGC alterations similar to those found with the continuous method. Yet, we highlight that care must be taken when interpreting 
our results, mainly due to the small number of studies that analyzed the exercise intensities on the analyzed variable. In this sense, it seems that the interval method can be adopted as a more attractive alternative to the individuals, due to the alternation of intensities during the session, which may ensure a greater adherence to training. Moreover, exercise therapists can prescribe aerobic training periodization with variation of training models (continuous and interval), making exercise even more dynamic and attractive. Taking into account the studies of the literature concerning acute aerobic exercise effects on $\mathrm{TGC}^{6-9}$, the exercise dosage necessary can comprise sessions lasting at least 30 to 45 minutes, with intensities varying from $80 \%$ and 100\% HRAT, 50 to $80 \%$ of peak oxygen consumption or at the intensities 13-17 of the Borg Scale (6-20). However, care must be taken because no study has yet tested different exercise dosages that could confirm the minimal dosage needed.

In the individual responsiveness analysis, it was shown that most patients were responsive to the aerobic protocols proposed regarding the immediate response to exercise (immediately after exercise), and the late response (30 minutes post-session), without difference between the prescription methods. However, it is important to highlight the absence of a single pattern of change, that is, some participants had their TGC levels increased, whereas others showed reductions. In addition, some patients were more responsive to the continuous protocol, whereas the others were more responsive to the interval. These findings demonstrate the importance of an individualized prescription for dyslipidemic patients.

Regarding the relationship between the acute and chronic effect of aerobic training on TG, it is possible that, at least in part, the sum of the acute effects contributes to the chronic benefits. However, there are few studies evaluating both acute and chronic effects of aerobic training on $\mathrm{TG}^{7,29}$. Still, these studies do not consider important aspects for understanding the acute responses along the interventions and their relationship with chronic findings, as adjustment of the relative intensity along the training process, relationship between acute TG alterations and pre-session values, among others. Although more studies are needed, training status of participants and relative intensity throughout the interventions need to be considered in clinical trials so that the relationship between acute and chronic responses is more safely established.

Although the present study brings relevant results, it is possible to highlight some limitations, as the absence of TGC assessment in periods longer than $30 \mathrm{~min}$, i.e. 24 and 48 hours after exercise, which would allow comparisons with the other studies previously performed, adding information about responses to interval exercise and indicating the real action time of lipids response mechanisms. Also, the lack of assessment of blood lipoproteins (LDL and HDL) and total cholesterol is another limitation, as it could provide us a better understanding of the acute responses of other lipid profile parameters to the aerobic training sessions proposed. Furthermore, the LPL enzyme evaluation would have been an important complement for the establishments of these responses. We can also highlight the absence of a control session (in which the participants did not perform any activity) being a suggestion for future studies. On other hand, the present study has some strengths, which evaluated TGC responses to two different models of aerobic exercise, prescribed in relation to $\mathrm{HR}_{\mathrm{AT}}$ in a cross-over randomized design, with findings presented by group (all patients) and individually (responsiveness analysis).

It is concluded that in dyslipidemic patients both continuous and interval aerobic exercise sessions provokes an immediate elevation in TGC, reducing already to 30 minutes after the sessions.

\section{Conflict of interest}

The authors declare no conflict of interest.

\section{Authors' contributions}

Santiago E participated in the initial design of the study, writing, literature search, data collection, data tabulation, analysis and conclusions of the study. Costa RR participated in the initial study design, data tabulation and study conclusions. Delevatti RS participated in the initial study design, data tabulation and study conclusions. Bracht CG participated in the writing, critical review of the text, translation into English and data collection. Preissler AAB, Silveira G, Fracalosi DG, Silveira Júnior and Rocha VMB participated in the data collection. Barroso BM and Reichert T participated in the data collection and critical review of the text. Kruel LFM participated in the initial study design and study conclusions.

\section{Acknowledgements}

The authors would like to thank CAPES and CNPq for their research support.

\section{References}

1. Gau GT, Wright RS. Pathophysiology, diagnosis, and management of dyslipidemia. Curr Probl Cardiol. 2006;31:445-86. 
2. Jellinger PS, Handelsman Y, Rosenblit PD, Bloomgarden ZT, Fonseca VA, Garber AJ, et al. $1 \mathrm{CPG}$ for managing dyslidemia and prevention of CVD. Endocr Pract. 2017;23 Suppl. 2:1-87.

3. Durstine JL, Davis PG, Ferguson MA, Anderson NL, Trost $\mathrm{SG}$, et al. Effects of short-duration and long-duration exercise on lipoprotein(a). Med Sci Sports Exerc. 2001;33:1511-16.

4. Lemes IR, Turi-Lynch BC, Cavero-Redondo I, Linares SN, Monteiro HL. Aerobic training reduces blood pressure and waist circumference and increases HDL-c in metabolic syndrome: a systematic review and meta-analysis of randomized controlled trials. J Am Soc Hypertens. 2018;12:580-88.

5. Costa RR, Buttelli ACK, Coconcelli L, Pereira LF, Vieira AF, Fagundes AO, Farinha JB, Reichert T, Stein R, Kruel LFM. Water-based aerobic and resistance training as a treatment to improve the lipid profile of women with dyslipidemia: a randomized controlled trial. J Phys Act Health. 2019;16(5):348-54.

6. Grandjean PW, Crouse SF, Rohack JJ.Influence of cholesterol status on blood lipid and lipoprotein enzyme responses to aerobic exercise. J Appl Physiol. 2000; 89:472-80.

7. Crouse SF, O'Brien BC, Grandjean PW, Lowe RC, Rohack J, Green J. Effects of training and a single session of exercise on lipids and apolipoproteins in hypercholesterolemic men. J Appl Physiol. 1997;83:2019-28.

8. Crouse SF, O’Brien BC, Rohack JJ, Lowe RC, Green J, Tolson $\mathrm{H}$, et al. Changes in serum lipids and apolipoproteins after exercise in men with high cholesterol: influence of intensity. J Appl Physiol. 1995;79:279-86.

9. Weise SD, Grandjean PW, Rohack JJ, Womack JW, Crouse SF. Acute changes in blood lipids and enzymes in postmenopausal women after exercise. J Appl Physiol. 2005;99:609-15.

10. Parto P, Lavie CJ, Swift D, Sui X. The role of cardiorespiratory fitness on plasma lipid levels. Expert Rev Cardiovasc Ther. 2015;13:1177-83.

11. Nobrega ACL. The subacute effects of exercise: concept, characteristics, and clinical implications. Exerc Sport Sci Rev. 2005;33:84-87.

12. Ferguson MA, Alderson NL, Trost SG, Essig DA, Burke JR, Durstine JL. Effects of four different single exercise sessions on lipids, lipoproteins, and lipoprotein lipase. J Appl Physiol. 1998;85(3):1169-74.

13. Borg G. Borg's perceived exertion and pain scales. Human Kinetics, Champaign, 1998.

14. Petroski EL. Antropometria - Técnicas e padronizações, 5 th ed. Ed. Jundiaí, Fontoura, 2011.

15. Siri WE. Body composition from fluid spaces and density: analysis of methods. Nutrition 9:480-91; discussion 480, 492, 1961.

16. Conconi F, Borsetto C, Casoni I, Graui G, Guglielmini C, Manfredini F, et al. The methodology of the "Conconi test." Oster J Sport. 1992;2:35-44.

17. Delevatti RS, Kanitz AC, Alberton CL, Pantoja PD, Marson EC, Pinho CDF, et al. Heart rate deflection point as an alternative method to identify the anaerobic threshold in patients with type 2 diabetes, Apunt. Medicina de l'Esport. 2015;50:123-28.
18. Howley ET, Bassett DR, Welch HG. Criteria for maximal oxygen uptake: review and commentary. Med Sci Sports Exerc. 1995;27:1292-1301.

19. Álvarez C, Ramírez-Campillo R, Ramírez-Vélez R, Izquierdo M. Effects and prevalence of nonresponders after 12 weeks of high-intensity interval or resistance training in women with insulin resistance: a randomized trial. J Appl Physiol. 2017;122(4):985-96.

20. Atkinson G, Batterham AM. True and false interindividual differences in the physiological response to an intervention. Exp Physiol. 2015;100:577-88.

21. Hopkins WG, Marshall SW, Batterham AM, Hanin J. Progressive Statistics for Studies in Sports Medicine and Exercise Science. Med Sci Sport Exerc. 2009;41:3-13.

22. Brouns F, Van der Vusse GJ. Utilization of lipids during exercise in human subjects: metabolic and dietary constraints. Br J Nutr. 1998;79:117-28.

23. Mougios V, Kotzamanidis C, Koutsari C, Atsopardis S. Exercise-induced changes in the concentration of individual fatty acids and triacylglycerols of human plasma. Metabolism. 1995;44:681-88.

24. Wahrenberg H, Engfeldt P, Bolinder J, Arner P. Acute adaptation in adrenergic control of lipolysis during physical exercise in humans. Am J Physiol Metab. 1987;253:E383E390.

25. Nikkilä EA, Taskinen MR, Rehunen S, Härkönen M. Lipoprotein lipase activity in adipose tissue and skeletal muscle of runners: relation to serum lipoproteins. Metabolism. 1978;27:1661-67.

26. Kantor MA, Cullinane EM, Herbert PN, Thompson PD. Acute increase in lipoprotein lipase following prolonged exercise. Metabolism. 1984;33:454-57.

27. Garber CE, Blissmer B, Deschenes MR, Franklin BA, Lamonte MJ, Lee I, et al. American College of Sports Medicine position stand. Quantity and quality of exercise for developing and maintaining cardiorespiratory, musculoskeletal, and neuromotor fitness in apparently healthy adults: guidance for prescribing exercise. Med Sci Sports Exerc. 2011;43:1334-59.

28. Yost TJ, Jensen DR, Haugen BR, Eckel RH. Effect of dietary macronutrient composition on tissue-specific lipoprotein lipase activity and insulin action in normal-weight subjects. Am J Clin Nutr. 1998;68:296-302.

29. Mora-Rodriguez R, Ortega J, Hamouti N, Fernandez-Elias V, Cañete Garcia-Prieto J, Guadalupe-Grau A, et al. Timecourse effects of aerobic interval training and detraining in patients with metabolic syndrome. Nutr Metab Cardiovasc Dis. 2014;24:792-98. 